\title{
ANÁLISE SOBRE AS DEFINIÇÕES TERRITORIAIS DE CIDADE, MUNICÍPIO E METRÓPOLE NA DIVERSIDADE DO TERRITÓRIO BRASILEIRO.
}

\section{Analysis of the territorial definitions of city, municipality and metropolis in the diversity of the Brazilian territory}

\section{Análisis sobre las definiciones territoriales de ciudad, municipio y metrópole en la diversidad del territorio brasileño}

\author{
Daniela Andrade Monteiro Veiga ${ }^{1}$ \\ Jana Maruska Buuda da Matta ${ }^{2}$ \\ Artur José Pires Veiga ${ }^{3}$
}

\footnotetext{
${ }^{1}$ Professora Adjunto do DCET/UESB, Vitória da Conquista - BA/Brasil. e-mail: dmonte_arq@ yahoo.com.br

${ }^{2}$ Professora Titular do DG/UESB, Vitória da Conquista - BA/Brasil. e-mail: janamaruska@ hotmail.com

${ }^{3}$ Professor Titular do DG/UESB, Vitória da Conquista - BA/Brasil. e-mail: tuka1000@ hotmail.com
}

\begin{abstract}
Resumo
Este artigo objetiva uma discussão sobre os critérios para definição de cidades, meio urbano e suas delimitações no território. Critérios para elucidar discussões político-administrativas e geográficas baseado na conceituação fornecida pelo IBGE, elaboradas para a realização dos censos, que repercutem na tomada de decisões de planejamento urbano e gestão política. Os procedimentos se fundamentam nas ferramentas de geoprocessamento, analises vetoriais referente as poligonais resultantes de operações geométricas que definem as cidades, áreas urbanas, rurais, municípios, metrópoles e regiões, ao passo que, os dados alfanuméricos associados a essas poligonais, são representados por população, domicílios, renda, saneamento, arrecadação de impostos, distribuição de recursos federais, dentre outros. Portanto, no âmbito dessa delimitação perpassam muitas questões, que norteiam a legislação do uso do solo, as políticas públicas, a aplicação de recursos e esforços onde for necessário melhorar as condições do ambiente construído em suas diferentes escalas e complexidades.
\end{abstract}

Palavras chaves: Limite; Cidade; Metropolização.

\begin{abstract}
This article discusses the criteria for defining cities, the urban environment and their delimitations in the territory. Criteria for elucidating political-administrative and geographic discussions based on the IBGE's conceptualization, elaborated for the accomplishment of censuses, that have repercussions in the decision making of urban planning and political management. The procedures are based on the geoprocessing tools, vector analysis for polygonal resulting from geometric operations that define cities, urban, countryside, municipalities, metropolis and regions, whereas alphanumeric data are associated with these polygons, represented by population, households, income, sanitation, collection of taxes, distribution of federal resources, among others. Therefore, within this delimitation, many questions arise, which guide the legislation of land use, public policies, the application of resources and efforts where it is necessary to improve the conditions of the environment built in its different scales and complexities.
\end{abstract}

Keywords: Limit; City; Metropolization.

\section{Resumen}


Este artículo objetiva una discusión sobre los criterios para la definición de ciudades, medio urbano y sus delimitaciones en el territorio. Criterios para elucidar discusiones político-administrativas y geográficas basado en los conceptos del IBGE, elaboradas para la realización de los censos, que repercuten en la toma de decisiones de planificación urbana y gestión política. Los procedimientos se fundamentan en las herramientas de geoprocesamiento, análisis vectoriales referentes a las poligonales resultantes de operaciones geométricas que definen las ciudades, áreas urbanas, áreas rurales, municipios, metrópolis y regiones, mientras que los datos alfanuméricos asociados a esas poligonales, son representados por población, domicilios, renta, saneamiento, recaudación de impuestos, distribución de recursos federales, entre otros. Por lo tanto, en el marco de esta delimitación pasan muchas cuestiones, que orientan la legislación del uso del suelo, las políticas públicas, la aplicación de recursos y esfuerzos donde sea necesario mejorar las condiciones del ambiente construido en sus diferentes escalas y complejidades.

Palabras claves: Límite; Ciudad; Metropolitan.

\section{Introdução}

O significado de cidade permeia outros conceitos como a dualidade entre zona urbana e ambiente urbano. Logicamente, a diferenciação está na oposição entre campo (zona rural) e cidade (zona urbana). Aqui não se pretende esgotar o tema para chegar a uma definição generalizante, pois as classificações efetuadas em diferentes estudos intervêm na própria conceituação de cidades, diante dos vários tipos e suas diferenças, por esse motivo aqui se propõe uma discussão sobre os critérios para definição de cidades, meio urbano e sua delimitação de espaço urbano.

Os estudos de Pelletier e Delfante (1997) buscou examinar várias cidades no mundo, do Ocidente incluindo as cidades que compõem o chamado Terceiro Mundo, do Islã até as cidades de tradição americana, sob diferentes aspectos, de forma didática e pragmática apresentaram as características das cidades, descrevem métodos de observação e análise, abordando o papel das cidades na organização do território. Nesse apanhado descritivo os autores relatam, ainda, a história do urbanismo, em todo seu pragmatismo, apresentando os problemas e as soluções adotadas nas cidades. Quando analisaram o crescimento das cidades, destacaram que tanto a cidade do México quanto São Paulo ultrapassaram, em população e centralização de serviços, as clássicas metrópoles como Londres, Nova Iorque, Moscou e mesmo Paris. Por conseguinte, esses autores assinalam que:

No final deste exame, demasiado rápido, dos grandes traços que caracterizam as cidades e as políticas de urbanismo no mundo de hoje, parece impor-se a verificação de um facto. No planeta inteiro de formas mais ou menos diversificadas, o fenómeno urbano é objeto de um real desenvolvimento descontrolado. Doravante, o crescimento das 
cidades afecta o mundo inteiro com taxas de aumento brutal no Terceiro Mundo (PELLETIER; DELFANTE, 1997, p.325).

Vale destacar com base nessa análise de Pelletier e Delfante que a divisão administrativa dentro de um Estado, no caso do Brasil, está determinada por instrumentos de divisão política do território e é limitada a critérios constantes em estudos, principalmente, respaldo pelo IBGE, sobre a classificação das cidades, e estão associados à existência de infraestrutura, transporte, serviços, equipamentos de lazer, cultura, comércio, consumo, auferidos por fluxos e redes reunidos em torno de outros conceitos como urbano, urbanização e rede urbana.

Muitos são os estudos, ideologias e teorias sobre as possibilidades de classificação do território, dos municípios, das redes, das cidades, das áreas urbanas e rurais. Dentre esses, há sugestão de que a urbanização ultrapassou as fronteiras sócioespaciais, não somente entre cidade e interior, urbano e rural, centro e periferia, mas também entre escalas urbanas, regionais, nacionais e globais.

Sobre essa produção, e com base em diversas teorias sobre essa temática, Brenner (2014) destaca uma série de teses sobre o urbano, onde relata uma cronologia das teorias desde a contribuição de Castells (2000), que durante o capitalismo gerencial do Pós-Guerra era fundamentada na construção social do fenômeno urbano, associando o capitalismo, o papel do Estado à reprodução da força de trabalho. Destacou, ainda, a tese de Lefebvre (2014) sobre a urbanização completa da sociedade, e defendeu um novo modelo de urbanização, orientado para a re-apropriação coletiva e autogestão democrática do espaço planetário como trabalho da espécie humana.

Outras pesquisas recentes levam em consideração formas de entendimento com base em definições conceituais que sugerem a análise do espaço, como superfície, alterado pelo homem para adequá-lo às suas necessidades culturais, econômicas e sociais. Desse modo, cria possibilidades de classificação abarcando uma gama de construções teóricas que as definam com mais propriedade do que a dualidade entre urbano e rural. Como exemplo tem-se fazendas urbanizadas, com infraestrutura entremeadas por longas superfícies ocupadas por culturas permanentes e/ou temporárias marcando o espaço agrário, alterados pelo homem, embora não seja cidade, está dotado de alta tecnologia e infraestrutura necessária para a otimização da sua produção. 
Nesse contexto, todo o espaço deve ser compreendido, analisado, estudado, levando em consideração os processos capitalistas de urbanização ${ }^{4}$. As análises que partem do princípio de sínteses, criação de modelos da realidade, simplificações e estudo das partes para o entendimento do todo, passam a coexistir com análises complexas que juntas interagem em vários conhecimentos de áreas distintas, perspectivas e realidades diferentes sobre uma mesma realidade comum, interligada. Alguns termos surgiram dessa tendência, como multi, inter e trans disciplinares nas abordagens teóricas.

Nessa junção que englobam diferentes perspectivas, conduzem as análises à ampliarem e interagirem com espaços que estão além dos tradicionais centros de aglomeração, desde as agros zonas de captação industrial até espaços naturais, como os oceanos, desertos, selvas, montanhas estão se tornando parte integrante de uma paisagem operacional em todo o mundo para processos (capitalista) de urbanização.

As tipologias geográficas de urbanização já não podem ater-se apenas aos conceitos de cidades, regiões metropolitanas, metrópoles ou megalópoles. Atualmente, as conceituações deverão abarcar diversos padrões e percursos através da paisagem socioespacial planetária. Brenner (2014, p. 187), considera que:

[...] paradoxalmente, no momento que o urbano parece ter adquirido uma importância estratégica extraordinária em várias instituições, organizações, entre pesquisadores, atores e ativistas, a definição do seu contorno está fragilizada. [...] a condição urbana contemporânea se apresenta impossível de definição (Tradução nossa).

Diante desse paradoxo, o urbano não está definido, por estar presente nas mais distintas configurações do habitat humano, espalhadas por todo o mundo em escalas e intensidades diferentes. Seja nos estudos urbanos, econômicos, ambientais ou sociais, a urbanização é inerente ao processo de crescimento das cidades. E, de fato, é o conceito de urbanização que sustenta a afirmação de que uma "era urbana", começou devido à mudança da maioria da população global do interior para as cidades.

Os autores das teorias mais arrojadas e revolucionárias que intencionam promover a análise urbana sob uma perspectiva mais ampla da dualidade urbano/ rural,

\footnotetext{
${ }^{4}$ Sobre o conceito de processos capitalistas urbanos, ver publicação "Implosions/Explosions: Towards a Study of Planetary Urbanization", que reúne artigos de renomados estudiosos sobre o tema da urbanização planetária. Em comum, os autores possuem uma visão crítica em relação aos processos capitalistas de urbanização, em seus capítulos diferentes autores apresentam subsídios e ideologias para a formulação de uma nova teoria urbana mundial.

${ }^{5}$ O Programa das Nações Unidas para os Assentamentos Urbanos (ONU-Habitat 1996) declarou o advento de uma "era urbana", gerada pelo rápido crescimento da população mundial nas cidades. Essa visão urbano-cêntrica se propagou desde o final da década de 1990, se popularizou por meio de uma série de conferências temáticas desenvolvidas em algumas das principais metrópoles do mundo e esse termo ficou amplamente conhecido.
} 
cidade/campo, destacam a importância dos processos de aglomeração, a capacidade de concentração de fluxos, concentração de riquezas em pontos estratégicos do território (as metrópoles), mudanças de papéis em regimes de acumulação do capital e suas morfologias e configurações espaciais expressas de formas distintas.

O processo de urbanização no Brasil ocorreu de forma desigual. Poucas cidades concentram população e riqueza, ocupando uma pequena parcela do território. Por outro lado, milhares de pequenos centros urbanos inseridos em áreas rurais, vinculados muitas vezes à realização de atividades primárias ocupam mais de $90 \%$ do território brasileiro. Nesse sentido, a análise sob a ótica da estruturação de uma rede urbana entre cidades baseada nas relações de comércio, serviços, infraestrutura, cultura, comunicação, se reestruturam abarcando a noção de hierarquia, proximidade, fluxos, tornado mais complexa a relação entre as cidades que compõe a rede (BAKIS, 1993).

A organização do espaço em redes pode ser determinada pela tecnologia, pela cultura e pela organização da sociedade. No modo de produção capitalista é imposto o ritmo de acumulação que implica uma dotação diferencial de instrumentos de trabalho e isso resulta em uma distribuição no espaço definido por Santos (1977), como "desigual e combinado". Assim, as teorias coexistem no espaço em um determinado tempo. Moura (2009 p.20) argumenta que:

[...] ocorre um contínuo processo de modernização, que não atinge todos os lugares ao mesmo tempo, obedecendo aos estímulos do Estado e à lógica do capital. Esse processo define os usos do solo, a apropriação da natureza, as relações entre os lugares e a organização do espaço como um todo, fortemente marcado pelas desigualdades e seletividades.

Compreender a diversidade e a heterogeneidade expressas no espaço requer assumir que a estrutura espacial representa um "componente dialeticamente definido das relações de produção gerais, relações estas que são simultaneamente sociais e espaciais" (SOJA, 1993, p. 99). A urbanização com base nas relações entre processos de aglomeração e suas paisagens operacionais, inclui a intensificação das formas de uso da terra, coordenação logística e luta social e política.

As cidades compreendidas como a expressão das contradições presentes no processo de urbanização de um país possuem demandas e prioridades distintas, conforme sua realidade. As diferentes formas de classificá-las, analisá-las enfatizam a necessidade de abarcar parte considerável dessa complexidade e diversidade. Neste sentido, o conceito de metrópole, polo de centralidade social, econômica das 
aglomerações populacionais, podem ser interpretadas como uma, das muitas, dimensões e expressão morfológica da urbanização.

Na década de 1960, Davidovich e Geiger (1961, p.3), ao escreverem sobre os aspectos do fato urbano no Brasil, afirmam que os critérios oficiais de cidade variam de um país a outro e que no Brasil "o conceito oficial de cidade é de caráter político administrativo: são as sedes de municípios que em 1950 somavam 1825; as vilas, sedes de distrito, também são incluídas na categoria urbana". Ainda complementam afirmando que:

Esta generalização mascara, naturalmente, grandes contrastes: aí estão englobadas as sedes de extensos municípios da Amazônia, dotadas de população ínfima e centros importantes, como São Gonçalo e Nilópolis, cujos respectivos municípios possuem áreas reduzidas. Por outro lado, nem sempre a elevação de uma vila à categoria de cidade implica no seu desenvolvimento efetivo - muitas vezes é resultado de injunções políticas e financeiras. No entanto, algumas vilas apresentam população superior à de certas cidades: em 1950, São Gonçalo possuía 20.000 habitantes aproximadamente e a vila de Neves acima de 50.000 habitantes (DAVIDOVICH; GEIGER, 1961, p.3).

Observa-se que a divisão territorial empregada pelo IBGE (2013) ${ }^{6}$ interfere sobre um conjunto de determinações econômicas, sociais e políticas que dizem respeito à totalidade da organização do espaço nacional. A Divisão Regional do Brasil em microrregiões, mesorregiões partem de determinações mais amplas que buscam identificar áreas individualizadas em cada uma das Unidades Federadas - UF.

Nesse contexto, Veiga (2002, p.23) chama atenção para o fato de que o Brasil adota uma delimitação eminentemente legal e administrativa, ao contrário de muitos outros países onde "a delimitação do urbano e do rural resulta da combinação de critérios de tamanho, densidade da população, e da sua localização". Cumpre ressaltar que outros órgãos também realizam a composição de municípios em regiões, com os mesmos propósitos do IBGE.

Esse artigo parte da análise espacial de dados, em que as informações são representadas territorialmente, que elucidam, sob a perspectiva geográfica, as discussões sobre planejamento urbano e regional, com vistas a subsidiar as políticas administrativas em diferentes escalas (municipal, estadual e nacional) de forma dinâmica, associando o dado alfanumérico a sua localização territorial, potencializando assim as análises.

\footnotetext{
${ }^{6}$ A metodologia da divisão territorial realizada pelo IBGE, consultada em 30/01/2013, está disponível em http://www.ibge.gov.br/home/geociencias/geografia/default_div_int.shtm?c=1
} 
A relevância da institucionalização política administrativa das regiões, estados, municípios está na utilização dessas áreas na elaboração de políticas públicas visando subsidiar o sistema de decisões quanto à localização de atividades econômicas, sociais e tributárias, voltada para o planejamento, estudos e identificação das estruturas espaciais de regiões metropolitanas e outras formas de aglomerações urbanas e rurais.

Os procedimentos metodológicos deste estudo foram desenvolvidos com emprego das técnicas de geoprocessamento, nas análises espaciais, com estrutura de dados vetoriais vinculados a alfanuméricos, obtidos do IBGE. As poligonais resultantes de operações geométricas que definem as cidades, áreas urbanas, rurais, municípios, metrópoles, estados e regiões caracterizam os dados vetoriais, ao passo que, os alfanuméricos estão associados a essas poligonais, representados por população, domicílios, renda, saneamento, arrecadação de impostos, dentre outros.

Devido a extensa gama de informações recenseadas pelo IBGE, todas relevantes para o planejamento e gestão pública, este artigo evidenciou apenas a divisão territorial do Brasil e as possibilidades de agrupamento dos setores censitários, como fator primordial nas análises estatísticas das informações recenseadas.

Os dados foram analisados no QGis, um Sistema de Informação Geográfica (SIG) um software livre. A opção por este SIG justifica-se por ser um programa de domínio público que atendeu plenamente a necessidade desse estudo. Nesse sistema foi elaborado um banco de dados, direcionado a obter produtos que foram analisados em diferentes escalas, abarcando partes ou todo o território brasileiro. As bases cartográficas utilizadas, assim como as unidades territoriais que contém as informações analisadas, foram disponibilizadas pelo IBGE.

\section{Análises espaciais na diferenciação territorial no Brasil}

Devido a diversidade do território brasileiro foi fundamental que fosse estudada, desde as metrópoles até pequenos centros urbanos com baixo dinamismo econômico, nesse sentido cabe destacar alguns conceitos sobre as divisões territoriais adotadas, extraídos do IBGE, e a correlação com a informação espaciais associada ao limite municipal e ao limite da cidade.

Segundo o IBGE (2013, p.297-299) são estabelecidos os conceitos de:

Municípios - São as unidades autônomas de menor hierarquia dentro da organização político administrativa do Brasil. Sua criação, incorporação, fusão ou desmembramento se faz por lei estadual, 
observada a continuidade territorial, a unidade histórico-cultural do ambiente urbano e os requisitos previstos em Lei Complementar estadual. Estas transformações dependem de consulta prévia às populações diretamente interessadas, através de plebiscito. Regem-se por Leis Orgânicas, observados os princípios estabelecidos na Constituição Federal e na Constituição do Estado onde se situam, e podem criar, organizar e suprimir distritos, observada a legislação estadual.

Cidade - É a localidade onde está sediada a Prefeitura Municipal. É constituída pela área urbana do distrito-sede e delimitada pelo perímetro urbano estabelecido por lei municipal.

Distritos - São unidades territoriais administrativas subdivididas dos municípios. Sua criação, desmembramento ou fusão se faz por lei municipal, observada a continuidade territorial e os requisitos previstos em Lei Complementar estadual. Podem, a depender da legislação estadual, serem subdivididos, conforme o caso, em subdistritos, regiões administrativas, zonas e similares.

Área urbana - Área interna ao perímetro urbano de uma cidade ou vila, definida por lei municipal. Anteriormente, quando não existia legislação que regulamentasse as áreas urbanas de cidades ou vilas, o perímetro urbano foi traçado para atender a finalidade da coleta censitária.

Área rural - É definida no IBGE como toda área externa ao perímetro urbano.

Esses conceitos estão desdobrados em perímetros fechados, ou conjuntos de setores censitários, que classificam toda a superfície do território brasileiro. O IBGE periodicamente para a realização de cada Censo revisa os seus perímetros, que são elaborados baseados na logística da realização da coleta de dados e obedecem às delimitações estabelecidas pela legislação municipal, estadual e federal.

Destaca-se no conceito de cidade que a área urbana estabelecida pelo IBGE, nos municípios brasileiros, conceitualmente pode ser igual ou menor do que a estabelecida pela legislação municipal. Assim as cidades definidas pelo IBGE, ainda que possuam internos aos seus limites, áreas não urbanizadas ${ }^{7}$, é a delimitação mais precisa de onde no território municipal ocorre a concentração de pessoas e domicílios em situação urbana.

Na figura 1 foi analisada os conceitos extraídos do IBGE aplicados no município de Vitória da Conquista - Bahia, que tem área da cidade delimitada pelo conjunto de setores censitários, classificados como urbanos, pertencentes ao distrito sede e internos ao limite estabelecido pela legislação municipal. Vale destacar que, quando a cidade cresce ocupando toda a área limite do município, os dados censitários da área rural são inexistentes. A limitação física do crescimento das cidades é determinada

\footnotetext{
${ }^{7}$ Segundo do IBGE (2013) “Áreas não urbanizadas de cidade ou vila são classificadas como aquelas legalmente definidas como urbanas, caracterizadas por ocupação predominantemente de caráter rural,,
} 
administrativamente pelo perímetro do município que a contém. A diversidade das cidades brasileiras, sobrepostas a delimitação legal e administrativa está representada na figura 2, com os casos dos municípios situados no estado de São Paulo (região Sudeste) e Mato Grosso (região Centro-Oeste).

Figura 1 - Vitória da Conquista - BA: Delimitações territoriais - 2015

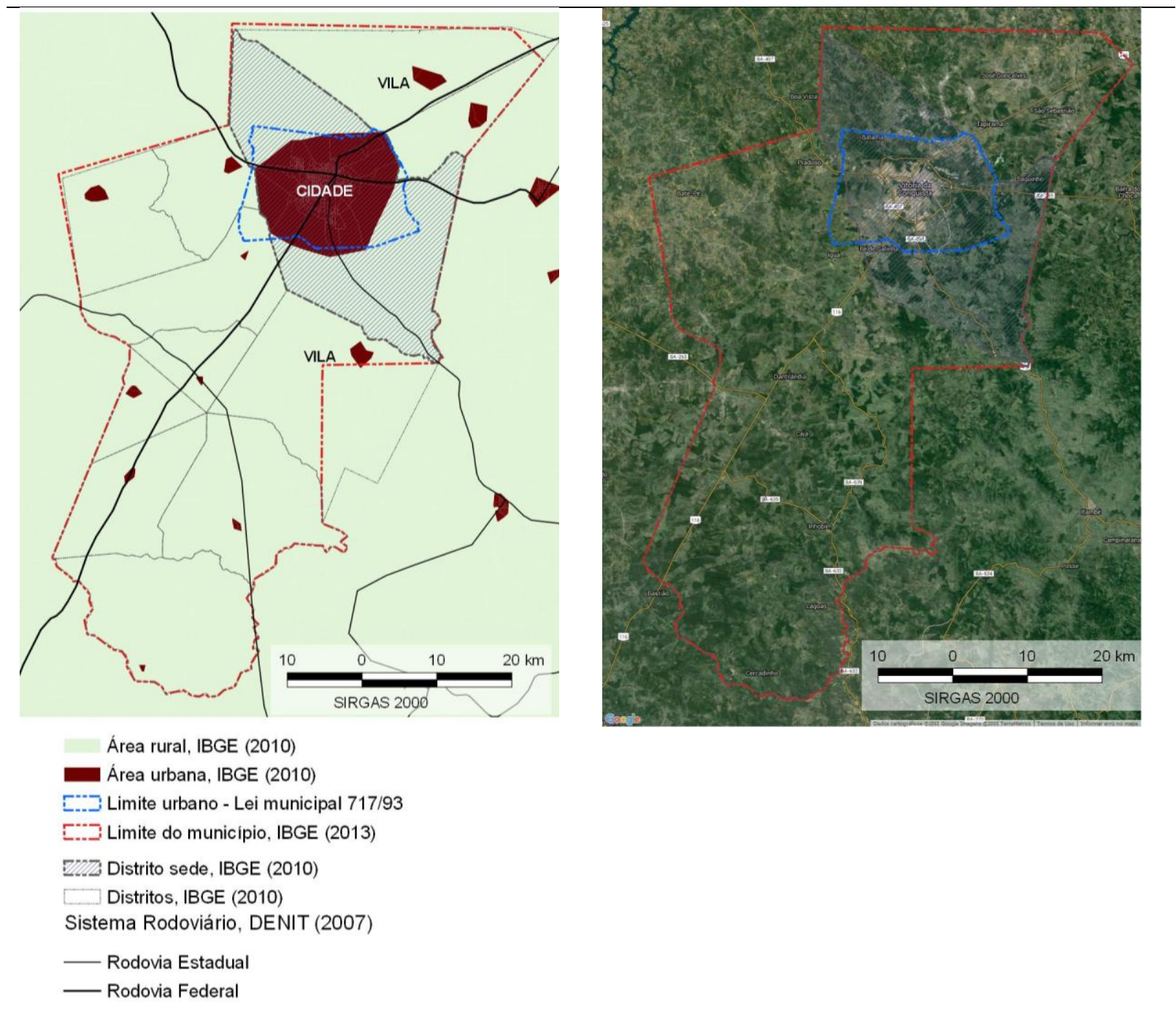

Fonte: Área urbana, área rural e distritos, IBGE (2010); Limite urbano estabelecido por lei municipal, In: Rocha e Ferraz (2015); Limite municipal IBGE (2013); Sistema rodoviário, DNIT (2007); Imagem do satélite CNES/ASTRUM (2014). Elaborado por Veiga, D.A.M. (2015).

Municípios como Osasco, Carapicuíba, Taboão da Serra, Diadema entre outros possuem menos disponibilidade de terras do que a própria capital do estado de São Paulo, que ao sul possui uma grande área de expansão. Salienta-se que o recorte das duas capitais São Paulo e Cuiabá, apresentados na figura 2, estão na mesma escala, possibilitando correlacionar o tamanho entre os municípios, áreas aglomeradas e a continuidade da malha urbana que ultrapassa os limites municipais. 
A visualização da informação alfanumérica associada aos limites territoriais entre cidades e/ou municípios possibilitaram análises mais dinâmicas que retratam uma gama maior de variáveis diretamente relacionadas ao planejamento urbano municipal, intermunicipal, estadual ou nacional.

Figura 2 - Distinções na delimitação municipal do Brasil - 2015

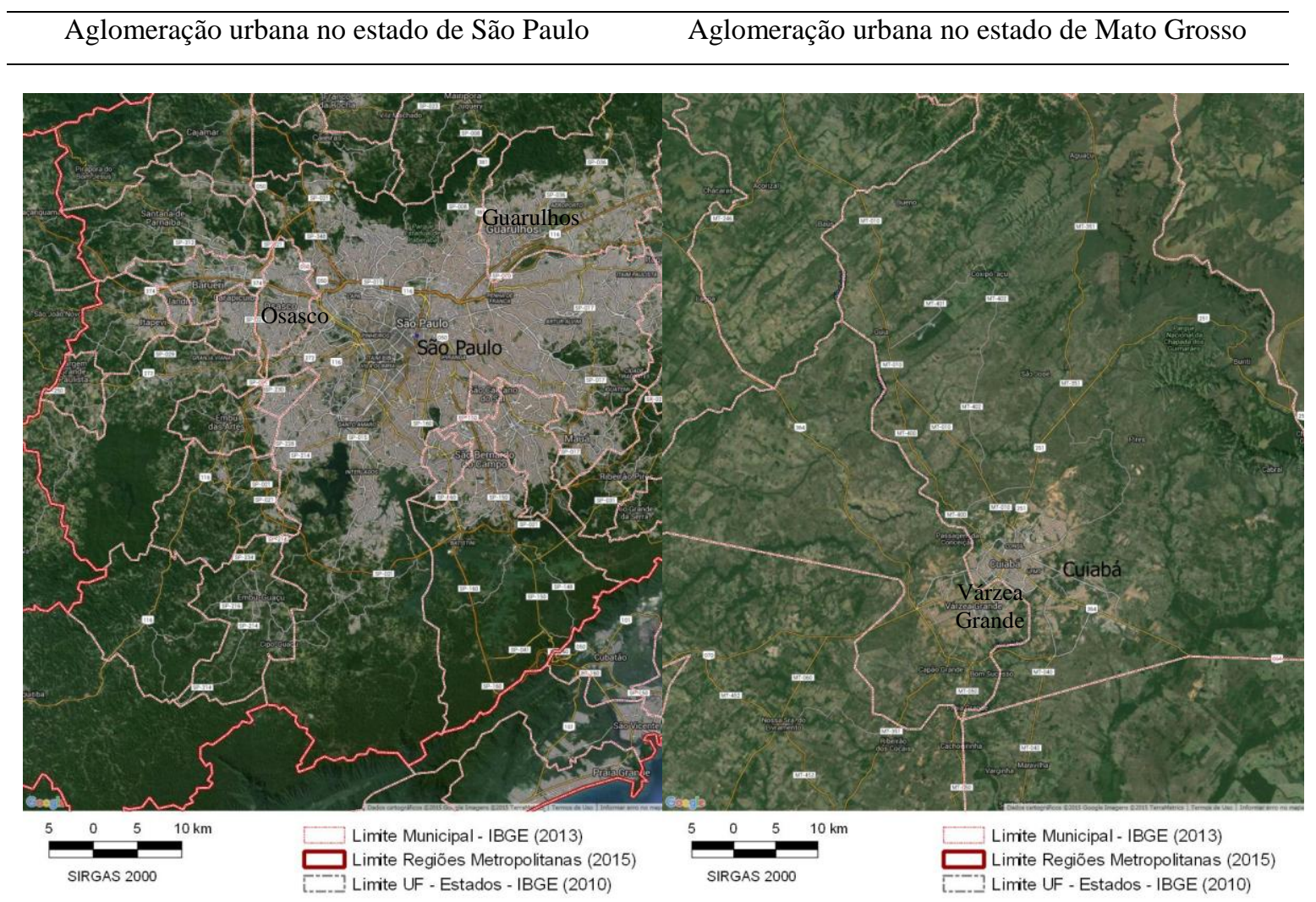

Fonte: Base cartográfica dos municípios, IBGE, 2013; Assembleias Legislativas Estaduais, Governos de Estado; Fórum Nacional de Entidades Metropolitanas - FNEM, 2015; Imagem do satélite CNES/ASTRUM, 2014.

Elaborado por Veiga, D.A.M. (2015).

Para ilustrar as possibilidades de análise relacionadas aos dados alfanuméricos e vetoriais, quando atingido a condição máxima de adensamento e ocupação do território municipal as demandas e déficits habitacionais se deslocarão para áreas territorialmente mais próximas, pertencentes a outros municípios. Nessa condição extrema, o déficit calculado para um município seria atendido pela produção habitacional realizada em um município vizinho. Todavia, mais do que questões mercadológicas de valorização do solo e especulação imobiliária algumas capitais apresentam indícios de insuficiência de terras, dentro do limite municipal, aptas para construção de habitações, em quantidades suficientes para suprir o déficit habitacional estimado para a sua população residente, ao 
mesmo tempo em que, justamente esses municípios apresentam maior incidência de domicílios vagos.

Questões que seriam particularmente analisadas em estudos locais, sem perder a noção da escala global e do entorno imediato, reforçam a necessidade de analises em diferentes escalas realizados de forma dinâmica e integrados. Ampliando essa análise territorial para todo do Brasil a figura 3 apresenta a delimitação das áreas urbanas e áreas rurais, estabelecida pela situação do setor censitário em 2010 e destaca os limites dos municípios que contém as capitais dos estados.

Figura 3-Brasil: Limite urbano / rural recenseado em 2010.

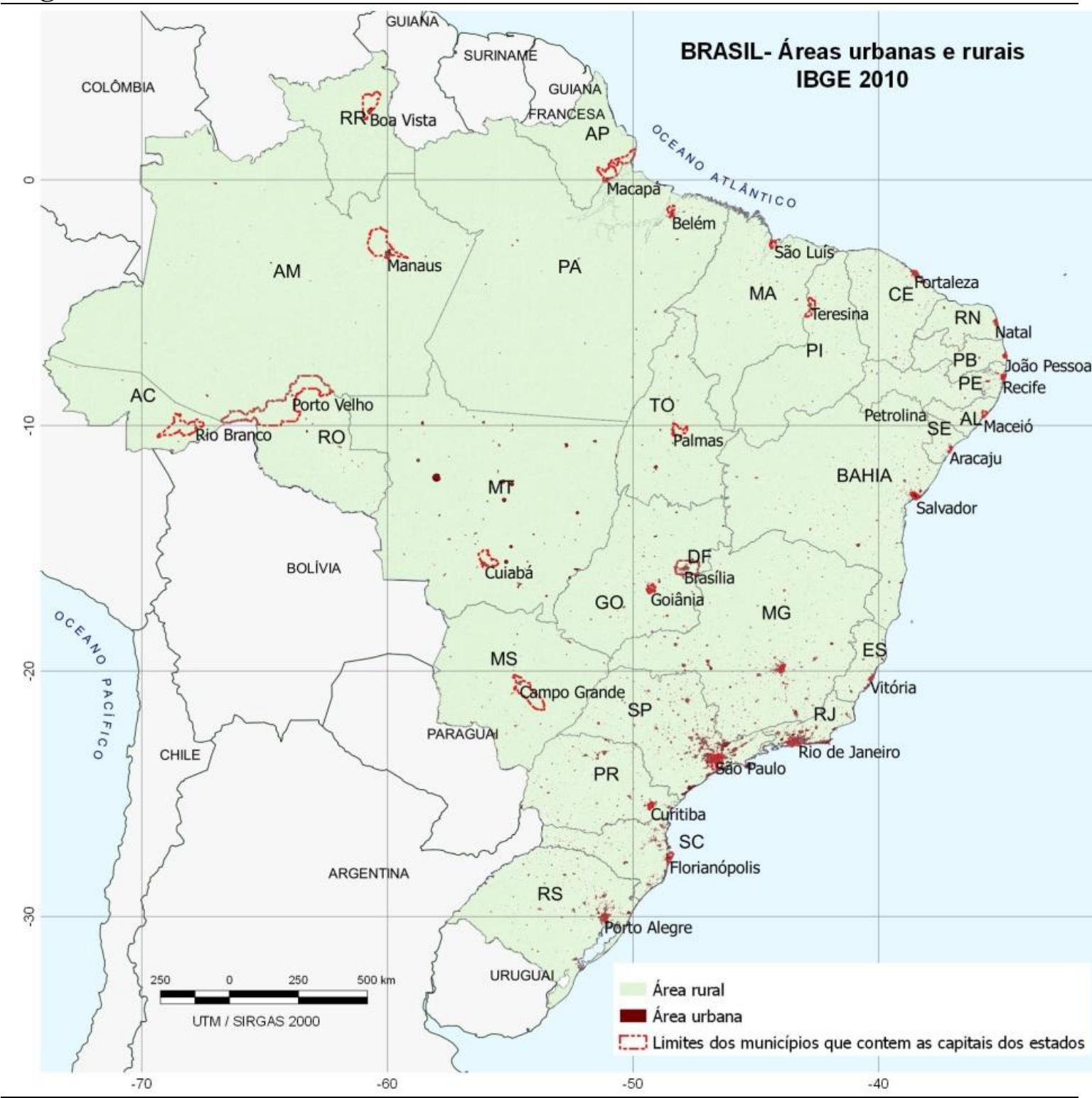

Fonte: Área urbana, área rural e distritos IBGE (2010); Limite municipal IBGE (2013). Elaborado por Veiga, D.A.M. (2015) 
A extensão das áreas rurais existentes entre áreas urbanas, assim como, as relações entre o tamanho dos municípios, cidades e vilas, influenciam diretamente nas estratégias de planejamento e gestão públicas. A diversificação da relação entre área urbana e rural que compõe os limites municipais de algumas capitais dos estados, ainda possuem áreas rurais apesar da conurbação com outros municípios. A figura 4 ilustra, na escala metropolitana, algumas capitais do Brasil.

Figura 4 - Área urbana nas cidades-capitais do Brasil - 2010

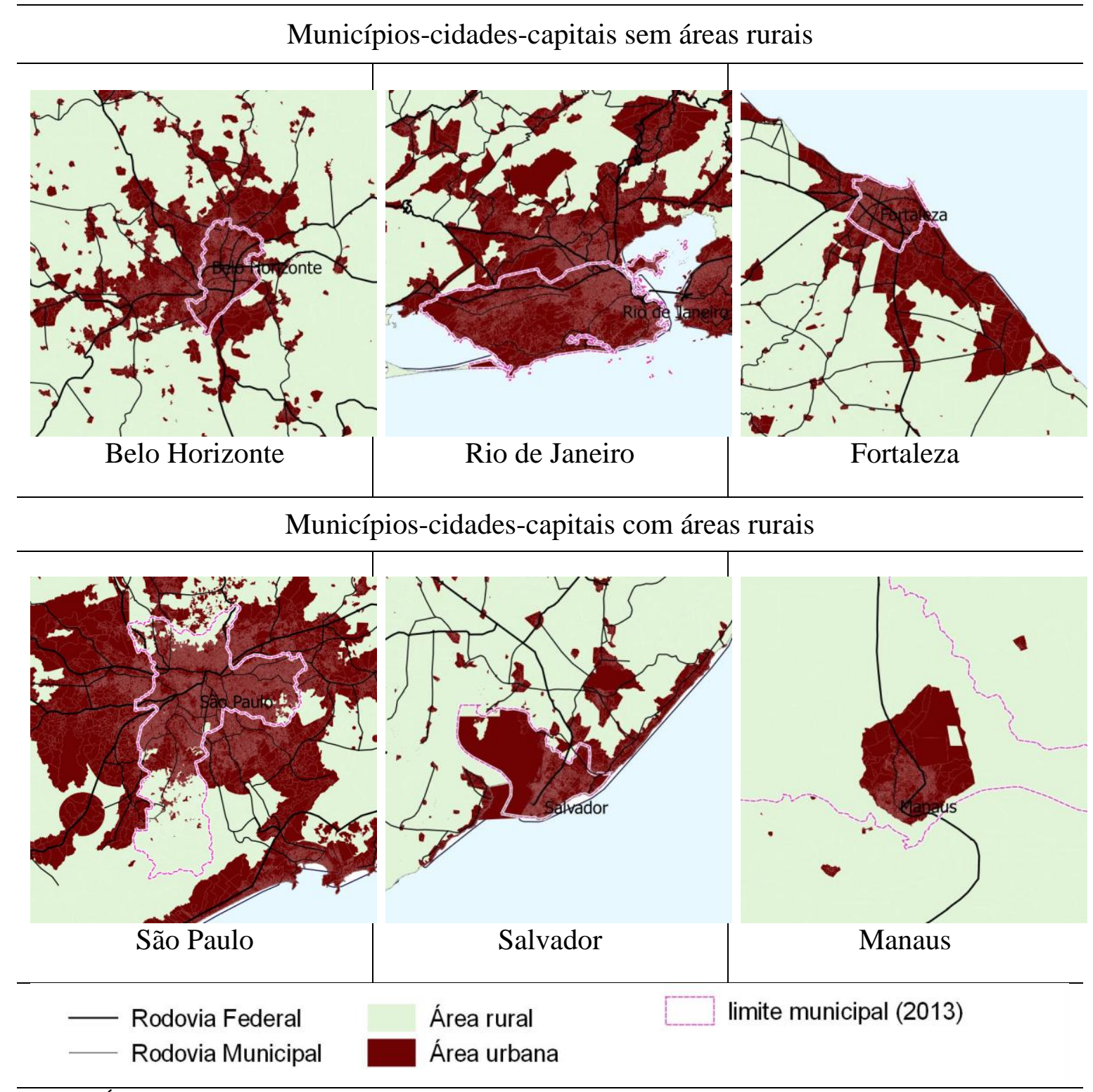

Fonte: Área urbana, área rural e distritos IBGE (2010); Limite municipal IBGE (2013). Elaborado por Veiga, D.A.M. (2015)

Todas as capitais apresentadas na figura 4 estão na mesma escala, podendo ser percebido as diferenças nas dimensões territoriais dos municípios e as equivalências nas 
extensões dos aglomerados urbanos. No caso especifico de Manaus, para permanecer a equivalência da escala, o limite municipal foi parcialmente apresentado.

$\mathrm{Na}$ diversidade brasileira coexistem municípios com grande extensão territorial, com pequenas cidades e grande capacidade territorial de crescimento, localizados predominantemente na região Norte e Centro-Oeste do país, em contraposição aos municípios com áreas menores com densidade populacional concentrada, ocupando integralmente a área urbana legalizada da cidade, correndo predominantes nas regiões Sul e Sudeste.

Sobre a informação especializada apresentada sob a forma de mapa ressalva-se que, para proceder com a interpretação do dado alfa numérico espacializado por município, que, ora remete exclusivamente ao dado das áreas urbanas, ora totaliza o dado para todo o município, é necessário a alteração da escala para melhor compreensão da ocorrência do fenômeno investigado no território. Essa recomendação ressalta a importância da informação ser interpretada simultaneamente com a leitura sobre a divisão política dos seus estados, municípios ${ }^{8}$ e áreas urbanas.

A região Norte comporta apenas 449 municípios, correspondendo a 8\% do total de municípios brasileiros. Uma disparidade em relação as regiões Sul e Sudeste que juntas equivalem a $51 \%$ dos municípios brasileiros. Essa estruturação territorial-administrativa interfere na representação política dos gestores municipais, que são mais numerosos na região Sul e Sudeste sendo responsáveis por administrar municípios menores, enquanto um número reduzido de representantes políticos é responsável por administrar e gerir diferentes demandas em grandes extensões de terras, na região Norte. As regiões Nordeste e CentroOeste possuem uma diversidade de municípios com tamanhos diferenciados e uma quantidade intermediária de representantes.

A diferenciação territorial e administrativa entre os municípios que integram as regiões do país influi na distribuição dos recursos da União, na capacidade administrativa municipal, dentre tantas outras questões, relacionadas à diversidade das demandas da população e seus gestores públicos, tanto na pluralidade dos municípios brasileiros quanto na capacidade de captação de recursos públicos.

\section{O falseamento do processo de metropolização no Brasil}

\footnotetext{
${ }^{8}$ Pode ser consultada a evolução da malha municipal 1940 - 2007, no Atlas do Brasil, IBGE 2007.
} 
A discussão do processo de metropolização e a hierarquização dos municípios na estruturação urbana do Brasil é recorrente e está presente em publicações como a do REGIC-IBGE (2008); IBGE (2011 e 2014); BITOUN, et all (2009); IPEA (2010 e 2013); GARSON (2009 e 2010); SILVA; SILVA; SILVA (2014). Estes estudos além de especializar territorialmente as Regiões Metropolitanas - RMs possibilitou identificar os municípios que as compõe, os qualificando de acordo com critérios próprios.

Figura 5 - Brasil: Regiões Metropolitanas - 2015

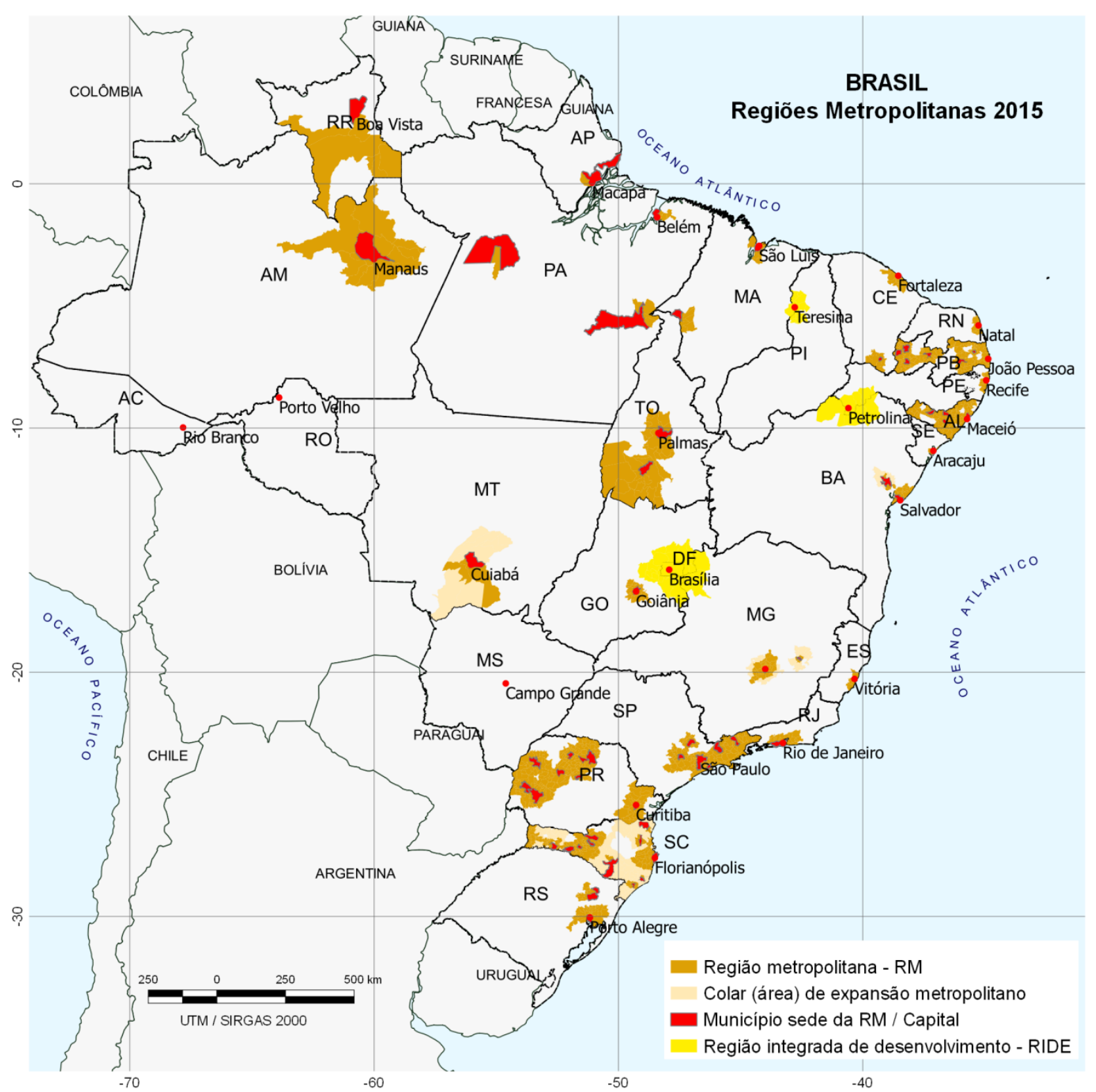

Fonte: Data de referência até fevereiro / 2015; Base cartográfica dos municípios, IBGE, 2013; Assembleias Legislativas Estaduais, Governos de Estado; Fórum Nacional de Entidades Metropolitanas - FNEM, 2015. Elaborado por Veiga, D.A.M. (2015). 
Com base nestes estudos o número de regiões metropolitanas em janeiro de 2009 eram 29 oficialmente instituídas, e em fevereiro de 2015 sendo contabilizadas 71 regiões metropolitanas ${ }^{9}$ (FIGURA 5) sem incluir os processos em andamento, ainda não publicados no Diário Oficial dos respectivos Estados. Em um quadro como esse, faz-se necessário conhecer a localização e dinâmica dessas RMs, entender como os municípios e as cidades que as compõe se relacionam, considerando o arranjo federativo brasileiro e os desafios que se impõe aos gestores públicos das diversas esferas de governo.

Figura 6 - Brasil: Área urbana recenseada em 2010 e limite das Regiões Metropolitanas em 2015

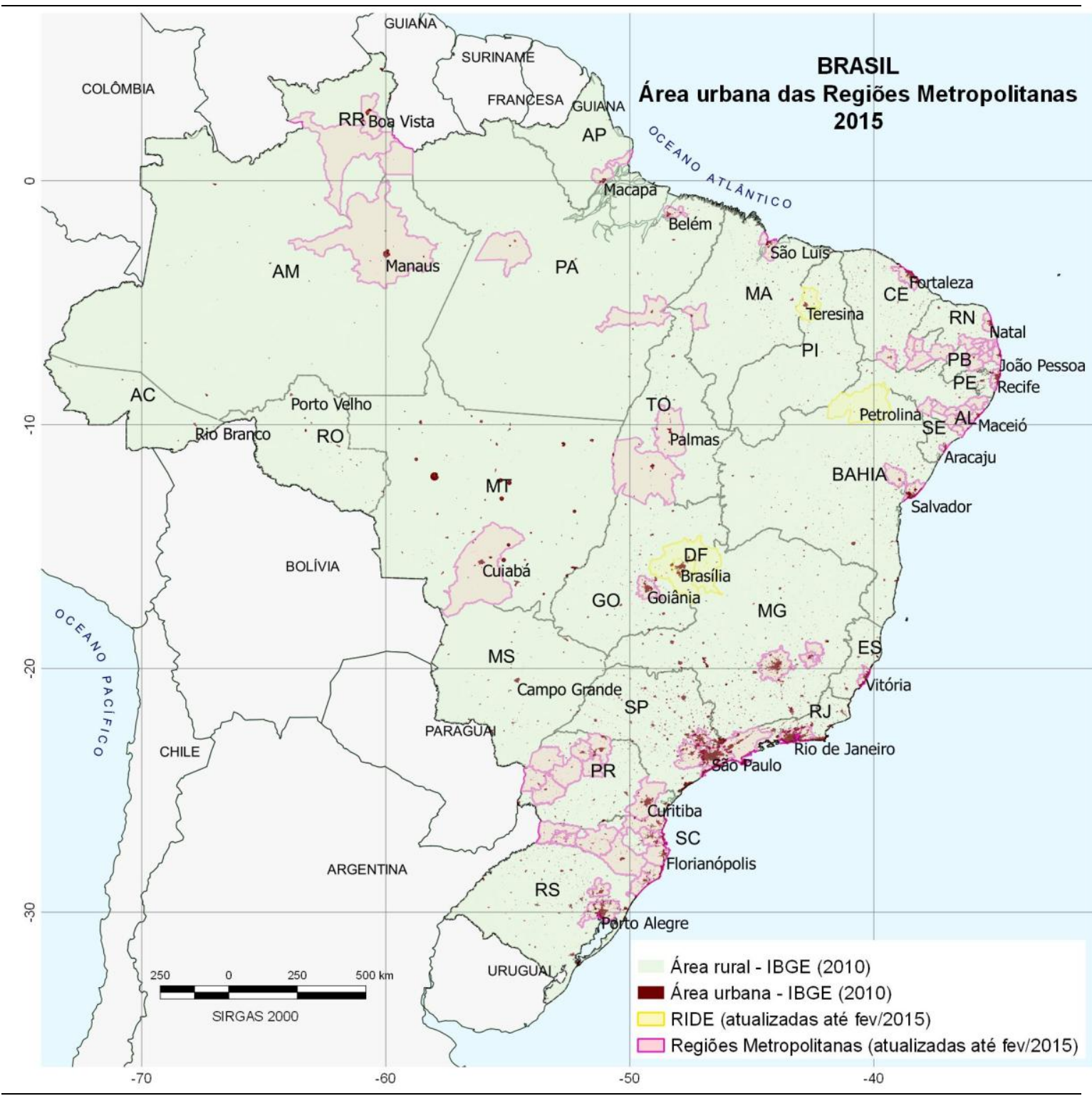

Fonte: Dados do censo 2010; Base cartográfica dos municípios, IBGE, 2013; Assembleias Legislativas Estaduais, Governos de Estado; Fórum Nacional de Entidades Metropolitanas - FNEM, 2015; Elaborado por Veiga, D.A.M. (2015).

${ }^{9}$ Conforme dados das Assembleias Legislativas Estaduais, Governos de Estado; Fórum Nacional de Entidades Metropolitanas - FNEM, até março/2015. 
Considerando a soma do território dos municípios integrantes de Regiões Metropolitanas, mais de $80 \%$ da área dos estados da Paraíba, Alagoas e Santa Catarina são compostos por regiões metropolitanas. Tocantins, Roraima, Amazonas e Paraná também aumentaram em número e extensão territorial a área ocupada pelas regiões metropolitanas de seus Estados.

A sobreposição das RMs e Regiões Integradas de Desenvolvimento - RIDEs apresentadas na figura 5 e sua correlação com as áreas urbanas apresentada, anteriormente, expõe uma falsa realidade no estabelecimento das áreas metropolitanas. A figura 6 ilustra a ocorrência das áreas urbanas, determinadas pelos critérios do IBGE, internas aos limites das RMs e RIDEs.

Constata-se que na maioria dos casos das RMs brasileiras, apresentadas na figura 6, a inexistência de aglomeração urbana na maioria dos municípios que a compõe, existindo apenas uma rede ou armações urbanas ${ }^{10}$ entre as cidades, situadas em municípios distintos, com maior ou menor grau de relações interdependentes e fluxos de pessoas e transações comerciais.

No conjunto de cidades unidas pela institucionalização de uma RMs, espera-se a cooperação mútua entre as administrações locais para a resolução de problemas comuns. Nos casos onde ocorreu a aglomeração urbana entre municípios, a interdependência dos serviços (transporte, hospitais, postos de saúde, escolas) torna a cooperação inevitável em alguns aspectos, devido à continuidade da área urbana e a necessidade mutua de seus cidadãos.

De acordo com as definições territoriais do IBGE, descritas anteriormente, nas áreas aglomeradas existentes dentro das regiões metropolitanas, ressalta-se que em alguns casos a cidade equivale a uma parcela da área urbana aglomerada interna ao limite do município. A diversidade das regiões metropolitanas existentes no Brasil, enfatizada pelos autores citados, é demonstrada neste estudo, na figura 7 que ilustra a situação de regiões metropolitanas com e sem a existência de metrópoles.

\footnotetext{
${ }^{10}$ Sobre o termo "armações urbanas" e a classificação hierárquica das cidades e das redes urbanas consultar Pelletier e Delfante (1997, p.111 - 125).
} 
Figura 7 - Extremos entre as Regiões Metropolitanas no Brasil - 2015
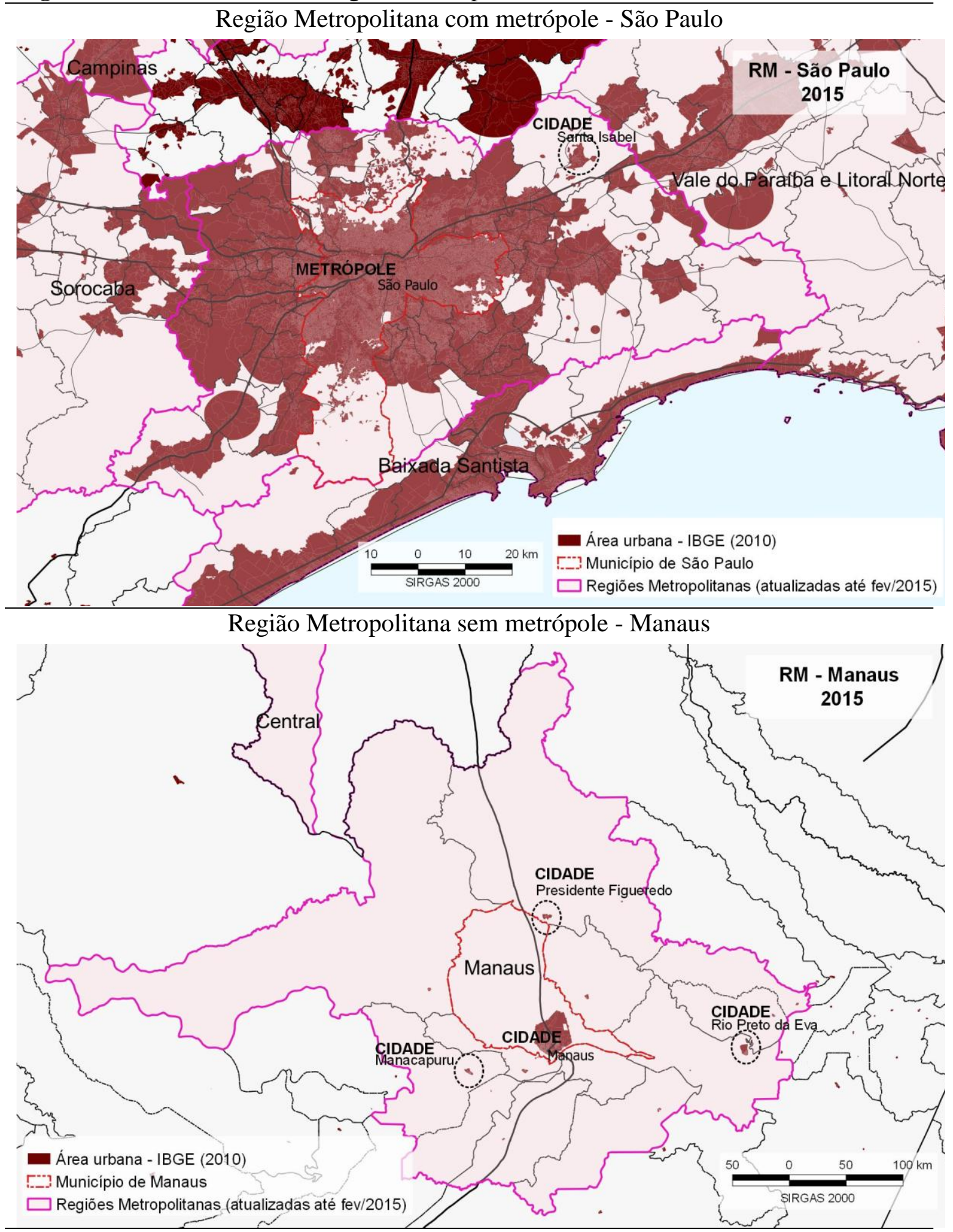

Fonte: Dados do censo 2010; Base cartográfica dos municípios, IBGE, 2013; Assembleias Legislativas Estaduais, Governos de Estado; Fórum Nacional de Entidades Metropolitanas - FNEM, 2015; Elaborado por Daniela A. M. Veiga, 2015.

Garson (2010) distingue os conceitos de Região Metropolitana e Metrópoles, sendo estas últimas, equivalente a uma parcela das áreas urbanas aglomeradas existentes dentro de uma ou mais Regiões Metropolitanas ou RIDE institucionalizadas por leis 
estaduais, pode também, ser representada pelo conjunto de cidades, internas as RM, que apresentam suas áreas continuas, ou espacialmente unidas na mesma classificação "urbana" além dos limites municipais ${ }^{11}$.

Observa-se que as principais cidades formadoras de Regiões Metropolitanas estão localizadas na costa, correspondendo à referência às capitanias hereditárias e ao processo de colonização do Brasil. No interior, como RM que possuem metrópoles, destaca-se apenas Belo Horizonte, Goiânia, RIDE de Brasília e Teresina. As demais RM correspondem a "armações espaciais furadas", classificadas de acordo com Pelletier e Delfante (1997, p.119) onde:

[...] são as que, dentro de um sistema regular no seu conjunto, aparecem lacunas, zonas menos urbanizadas, menos irrigadas pela cidade. As causas são múltiplas, mas concentram-se, no fato da presença de zonas menos utilizáveis ou um pouco ultrapassadas, ou ainda não aproveitadas nos países beneficiando uma margem pioneira. Desta forma existem zonas de sombra, espaços não metropolizados, à parte das influências das grandes cidades. [...] casos extremos, muito comum, os <<buracos〉> da armação espacial tem tendência para cobrir a maior parte do território. Estes tipos de armações permitem na realidade definir os países não urbanos mesmo que a população total do mesmo nome seja muito importante.

As análises realizada por Pelletier e Delfante (1997) trouxe a síntese da configuração espacial de cidades no mundo, na dimensão continental do Brasil e os "buracos" são territórios não urbanizados dentro de municípios integrantes de uma mesma RM. Exposto isso, a institucionalização de uma Região Metropolitana, conferida por uma Lei Complementar é insuficiente para considera-la como um território que possui uma relação de cooperação mutua sobre questões administrativas entre seus municípios, originada por um processo sócio espacial.

Mais que isto, a fragilidade e baixa efetividade dos arranjos institucionais, quando existentes, confrontam o próprio sentido dessa institucionalização. Costa (2013, p.325) defende a hipótese de que:

Considerando as características do federalismo brasileiro, em particular, a forma como os recursos tributários se encontra distribuídos entre União, Estados e Municípios e, sobretudo, a maior capacidade da União em disponibilizar recursos para os investimentos em infraestrutura social e urbana $[\ldots]$ nota-se que Estados e

\footnotetext{
${ }^{11}$ Durante o processo de experimentação para a formulação desta pesquisa, antes da adoção do conceito de cidade do IBGE, foram realizadas delimitações de áreas urbanas obtidas da interpretação de imagens de satélite e fotos aéreas. O conceito de metrópoles como áreas de aglomeração urbana interna as Regiões Metropolitanas aceita diferentes definições de área urbana.
} 
Municípios buscam na constituição das RMs uma forma de se qualificarem como elegíveis para receber investimentos federais. [...] o processo de metropolização institucional tem muito mais a ver com a limitada capacidade fiscal de municípios e estados e com a possibilidade que vislumbram de terem acesso a recursos tributários federais para a realização de investimentos em infraestrutura social e urbana que de outra forma não iriam acessar (na avaliação deles).

A análise feita por Silva, Silva e Silva (2014, p.39-40) ao comparar as diferenças entre as regiões metropolitanas afirmam que "as metrópoles brasileiras apresentam, em geral, uma relação tamanho-hierarquia no contexto da rede de cidades compatível com o modelo de ocupação do território". Destacam também que a "urbanização no interior" através da "constituição de uma rede cada vez mais numerosa de cidades médias com suas regiões de influência, tem sido uma expressão espacial da ocupação do território”... "Os dois processos - metropolização e urbanização no interior - que por sinal, estão integrados, precisam ser encarados como um desafio nacional na perspectiva do desenvolvimento regional”. Nessa delimitação entre quem é metrópole, quem está inserido em uma, quem faz parte da sua periferia ou colar metropolitano, e quem está fora delas, estão imbuídas muitas questões, uma delas é a captação/disponibilização dos recursos federais.

\section{Considerações finais}

A possibilidade de captação de recursos federais, a ser realizada individualmente por municípios que componham uma RM, é anunciada nos fóruns de discussão sobre o assunto como sendo uma das razões para institui-las. Ainda que se apresentem as competências e atribuições inerentes a essa regionalização, o imperativo da captação de recursos é o que se destaca nos debates e mobiliza o interesse da administração municipal.

Agrupando os municípios em conjuntos que expressem situações em comum, sempre foi abarcado todo o território brasileiro, a fim de orientar as políticas públicas a aplicar os seus recursos e esforços onde for necessário melhorar as condições do ambiente construído em suas diferentes escalas e complexidades.

Seja urbano, rural, cidade, capital, metrópole ou interior os desafios inerentes ao planejamento e gestão pública carecem de análises dinâmicas em diferentes escalas, norteadas pela apropriação coletiva das informações e autogestão democrática do espaço. Nesse sentido, o sistema de informações formulado neste estudo fomenta discussões sobre as possibilidades de agrupamento dos setores censitários, menor unidade de informação alfanumérica georreferenciada do IBGE. 


\section{Referências}

BAKIS, Henry. Les reseaux et leurs enjeux sociaux. Paris: Presses Universitaires de France, 1993.

BITOUN, Jan; MIRANDA, Lívia Izabel Bezerra; ARAÚJO, Tânia Bacelar; FERNANDES, Ana Cristina. Tipologia das cidades brasileiras. Rio de Janeiro: Letra Capital: Observatório das Metrópoles, 2009.

BRENNER, Neil. Theses on urbanization. In: BRENNER, Neil. Implosions/Explosions: towards a study of planetary urbanization. Berlin: Jovis Books, 2014.

CASTELLS, Manuel. A questão urbana. São Paulo: Paz e Terra, 2000.

COSTA, Marco Aurélio. Quarenta Anos de Regiões Metropolitanas no Brasil: um breve balanço exploratório. In: COSTA, Marco Aurélio; TSUKUMO, Isadora Tami Lemos (Orgs.) 40 anos de regiões metropolitanas no Brasil. Série Rede IPEA. Projeto Governança Metropolitana no Brasil, v. 1. Brasília: IPEA, 2013.

DAVIDOVICH, Fany Rachel e GEIGER, Pedro Pinchas. Aspectos do fato urbano no Brasil. Revista Brasileira de Geografia - RGB. Ano 23 n.2, abr/jun. Rio de Janeiro: IBGE, 1961.

GARSON, Sol. Regiões metropolitanas: por que não cooperam? Rio de Janeiro: Letra Capital: Observatório das Metrópoles; Belo Horizonte, MG: PUC, 2009.

; RIBEIRO, Luiz Cesar de Queiroz; RODRIGUES, Juciano Martins. Regiões Metropolitanas do Brasil. Observatório das Metrópoles IPPUR. Rio de Janeiro: IPPUR, URFJ, 2010

INSTITUTO BRASILEIRO DE GEOGRAFIA E ESTATÍSTICA - IBGE. A metodologia da divisão territorial realizada pelo IBGE. Disponível em: $<$ http://www.ibge.gov.br/home/ geociencias/geografia/default_div_int.shtm?c=1 $>$ Acesso em 30/01/2013.

Redes e fluxos do território. Rio de Janeiro: IBGE, 2014. 2008. Região de influência das cidades - REGIC 2007. Rio de Janeiro: IBGE,

Região metropolitana, RIDE ou aglomeração urbana. Rio de Janeiro: IBGE, 2011. Disponível em: <ftp://geoftp.ibge.gov.br/organizacao_territorial/municipios_por_regioes_ metropolitanas/rm_atualizada_2010.xls>. Acesso em 03/03/2012.

INSTITUTO DE PESQUISA ECONÔMICA APLICADA - IPEA. 40 anos de regiões metropolitanas no Brasil. Série Rede IPEA. Projeto Governança Metropolitana no Brasil; v. 1. Brasília: IPEA, 2013. 
Infraestrutura social e urbana no Brasil: subsídios para uma agenda de pesquisa e formulação de políticas públicas. Série Eixos Estratégicos do Desenvolvimento Brasileiro, livro 6. Brasília: IPEA, 2010.

LEFEBVRE, Henri. Dissolving city, planetary metamorphosis. In: BRENNER, Neil. Implosions/ Explosions: Towards a study of planetary urbanization, Berlin: Jovis Books, 2014.

PELLETIER, Jean e DELFANTE, Charles. Cidades e urbanismo no mundo. Tradução de Sylvie Canape, sl: Lisboa: Instituto Piaget, 1997.

SANTOS, Milton. Sociedade e espaço: a formação social como teoria e como método. Boletim Paulista de geografia, $n^{\circ}$ 54, São Paulo:1977.

SILVA, Sylvio Bandeira de Mello; SILVA, Barbara-Christine Nentwig; SILVA, Maina Pirajá. Regiões Metropolitanas na atualidade brasileira: um estudo comparativo. In:

CARVALHO, Inaiá Maria Moreira; et al. (Orgs.) Metrópole na Atualidade Brasileira: transformações, tensões e desafios na Região Metropolitana de Salvador. Salvador: EDUFBA, 2014.

SOJA, Edward. W. Geografias pós-modernas. A reafirmação do espaço na teoria social crítica. Rio de Janeiro: Jorge Zahar Editor, 1993.

VEIGA, José Eli da. Cidades Imaginárias: o Brasil é menos urbano do que se calcula. Campinas: Autores Associados, 2002.

Recebido em: 18/11/2017

Aceito para publicação em: 10/12/2017 